http://jmscr.igmpublication.org/home/ ISSN (e)-2347-176x ISSN (p) 2455-0450 crossref DOI: https://dx.doi.org/10.18535/jmscr/v8i4.12

\title{
A Study on Single Incision Multiport Laparoscopic Appendicectomy (SIMPLA)
}

\author{
Authors \\ Dr Narayanaswamy. $\mathbf{T}^{\mathbf{1}}$, Dr Neha.M.S ${ }^{2} *$ \\ ${ }^{1}$ Professor of Surgery, General Surgery \\ ${ }^{2}$ Resident (Second Year), General Surgery \\ *Corresponding Author
}

Dr Neha. M.S

\section{Introduction}

Appendectomy is one of the frequently performed procedures in general surgery. It is being performed by various techniques like open surgical, laparoscopic assisted, total laparoscopic multiport, single-incision laparoscopic and natural orifice transluminal endoscopic (NOTES) appendectomy ${ }^{[1][2][3]}$. Open and multiport laparoscopic techniques are frequently performed and are already established modalities. Single incision laparoscopic surgery (SILS) is a further step towards lesser invasive surgical procedure and could become an alternative to multiport laparoscopic appendectomy. But, it requires certain exclusive instruments, and expertise, which ultimately increases the cost of the procedure, especially in developing countries ${ }^{[4],[5]}$. The cost of SILS could be minimised by using conventional multiport instruments to devise a Single Incision Multiport Laparoscopic Appendicectomy (SIMPLA). The objective of this study is to evaluate the feasibility and safety of SILS appendectomy using conventional multiport laparoscopic instruments.

\section{Materials and Methods}

This prospective study was carried out in the General Surgery department of KEMPEGOWDA Institute of medical sciences over a period of 6 months from August 2019 to December 2019. In the present study, patients with acute appendicitis undergoing elective as well as emergency SIMPLA were included. All the surgeries were performed using conventional multiport laparoscopic instruments using a single incision technique. Patients were selected according to the following criteria.

\section{Inclusion Criteria}

Age $=12-60$ years

Clinically and/or sonographically proven acute appendicitis

No co-morbid conditions (ASA grades I and II)

\section{Exclusion Criteria}

Pregnancy

Morbid obesity

Multiple previous abdominal surgeries

Uncontrolled medical conditions

\section{Instrumentation}

Endovision: single-chip camera, halogen light source, $\mathrm{CO}$ insufflator

$10-\mathrm{mm} 30^{\circ}$ telescope 
5-mm $0{ }^{\circ}$ telescope

10 -mm trocar-1

5-mm trocar - 1

Atraumatic grasping forceps

Babcock's forceps

Bipolar diathermy forceps

Needloscopic instrument: epidural needle-based suture-loop grasper

Scissors

Position: Patient was positioned supine on the operating table with patient's left arm tucked, in Trendelenburg's position. The placement of operating surgeon, assistants and video cart are similar tothe conventional laparoscopic appendicectomy.

\section{Establishing the Ports}

Under general inhalational anesthesia, a $2.5-\mathrm{cm}$ single, curved, supra-umbilical incision made.

Pneumoperitoneum was created by open technique using blunt 10 -mm trocar.

Abdominal cavity was explored with $10-\mathrm{mm} 30^{\circ}$ telescope. Additional $5 \mathrm{~mm}$ port placed adjacent to the $10 \mathrm{~mm}$ port. In cases where another port was required, two 5-mm trocars were placed by the side of the first $10 \mathrm{~mm}$ trocar, one right inferolateral and one right supero-lateral (Mickey Mouse configuration), with the skin incision being single.
One additional needloscopic instrument for assistance through RIF was placed through which the extracorporeal knot made out of Prolene 1-0

\section{Procedure}

Abdominal cavity was explored with $10-\mathrm{mm} 30^{\circ}$ telescope. After confirmation of the diagnosis, the position of appendix was identified. The appendix is grasped with a 5-mm atraumatic grasper and fed into the prolene knot passed through the needloscopic instrument followed by which the knot was tightened and traction given to enable dissection. Further dissection carried out by the instruments passed through the $5 \mathrm{~mm}$ port adjacent to the $10 \mathrm{~mm}$ camera port. Mesoappendix was cauterized and incised with bipolar forceps. Appendix was dissected up to the base. Base was doubly ligated on the caecal side and singly ligated on specimen side with the endoloop and resected in between.

The $10-\mathrm{mm}$ telescope was replaced by $5-\mathrm{mm} 0^{\circ}$ telescope. Specimen was removed through the 10 $\mathrm{mm}$ port. The $10-\mathrm{mm}$ port site was sutured with non-absorbable suture. Skin was sutured with silk. The clinical, operative, and outcome data of all the cases were documented and analysed systematically.

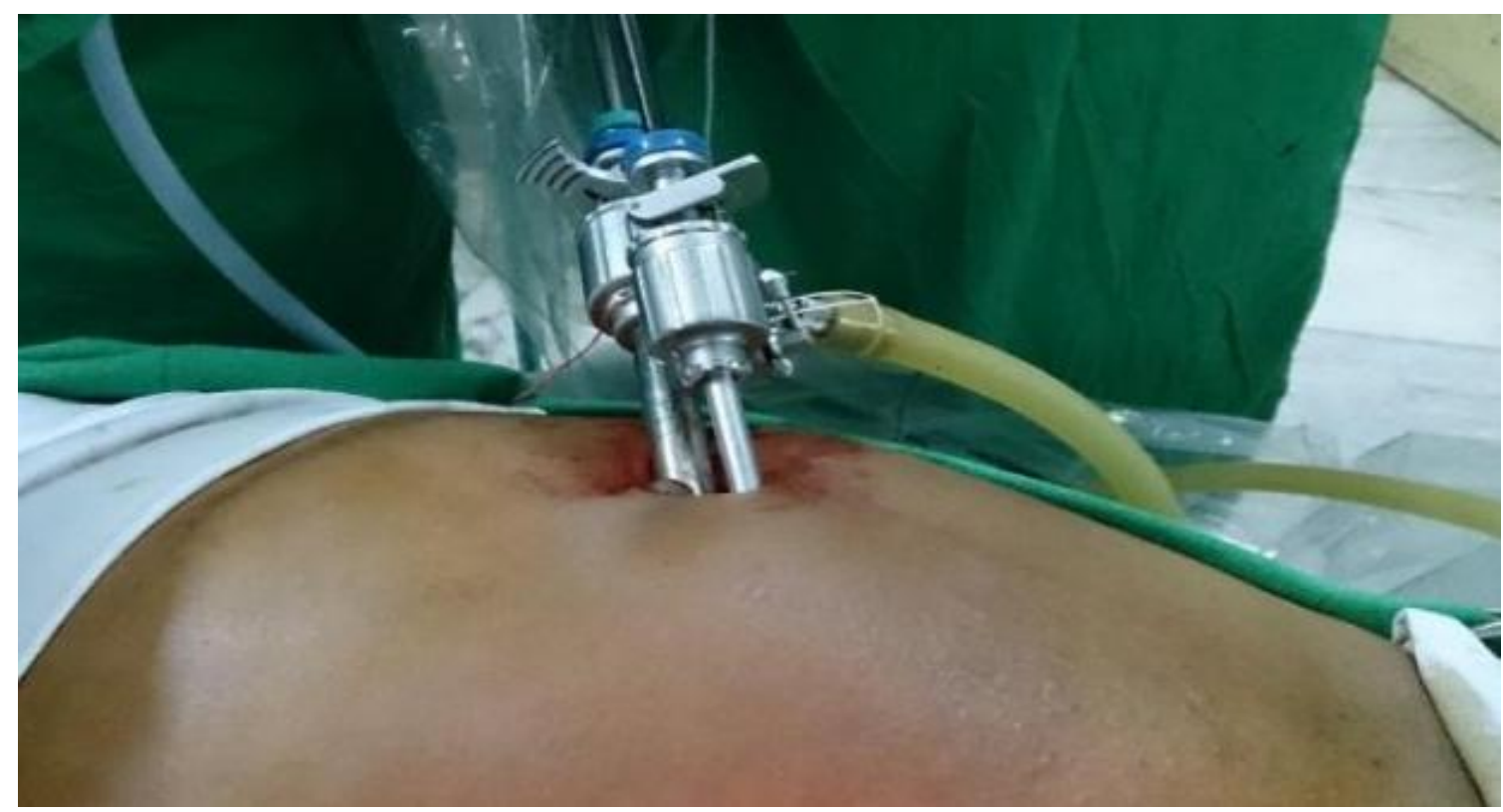

Fig 1: Placement of multiple ports through single skin incision 


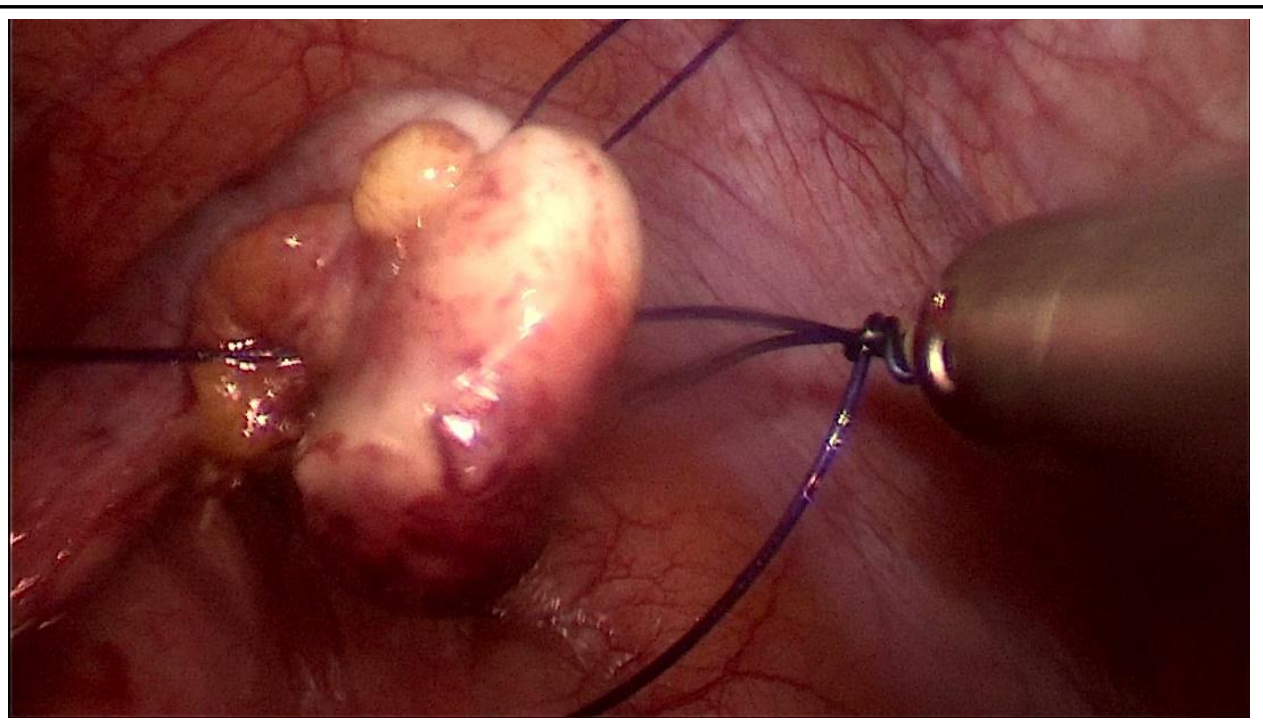

Fig 2: Appendix held in traction with help of prolene suture passed through the needloscopic instrument.

\section{Postoperative Care}

The patient is administered intravenous fluids, antibiotics, and analgesics. Oral feeds are commenced as appropriate depending on the degree of appendiceal inflammation and return of bowel function. Early mobilisation is encouraged and the patient is usually discharged on the first post-operative day.

\section{Results}

Tables 1, 2 and 3 summarise our early experience with SIMPLA.

\section{Table 1}

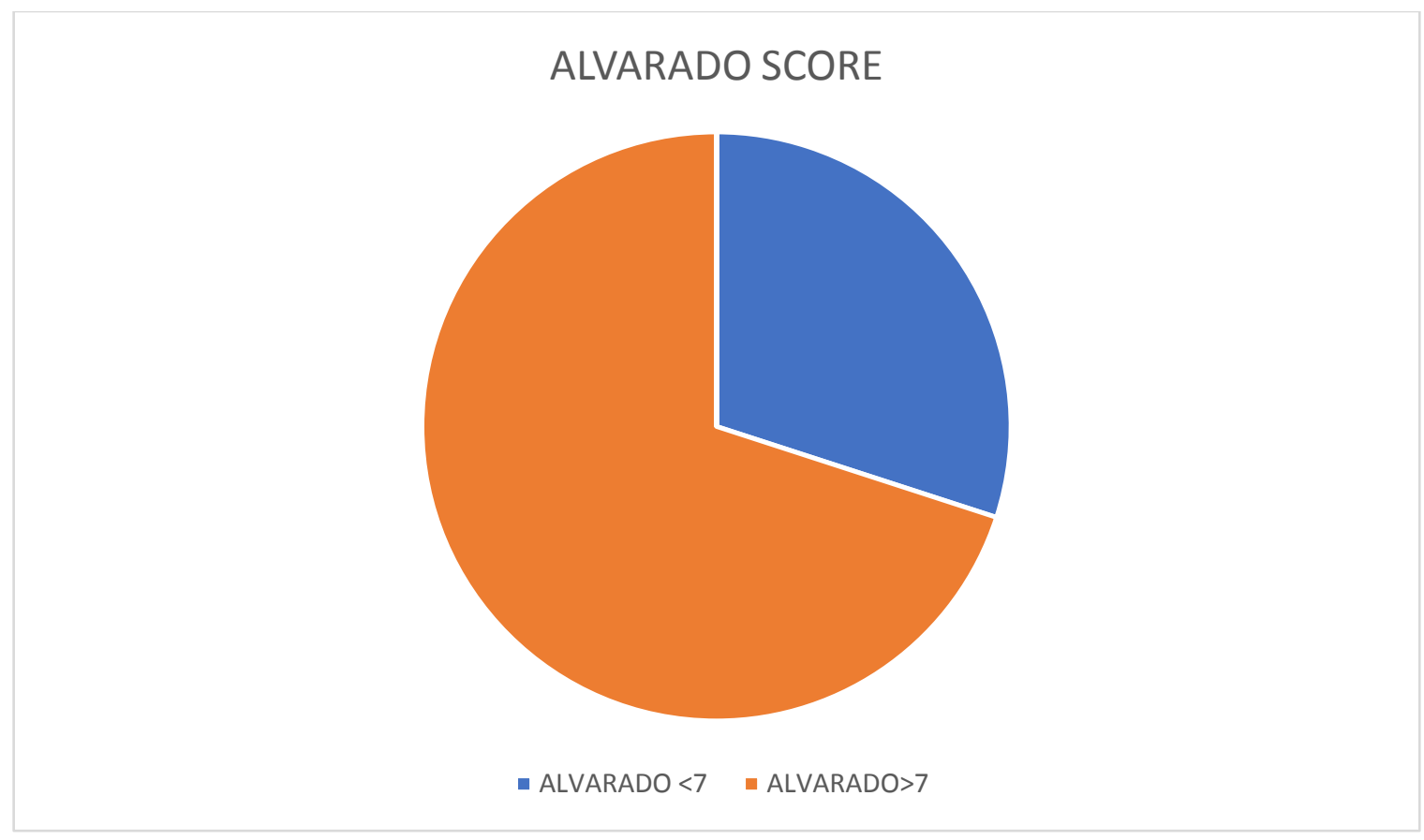

Out of the ten patients who underwent SIMPLA, 7 patients had Acute appendictitis with ALVARADO score $>7$ and three patients had acute appendicitis having ALVARADO SCORE $<7$. 
Table 2

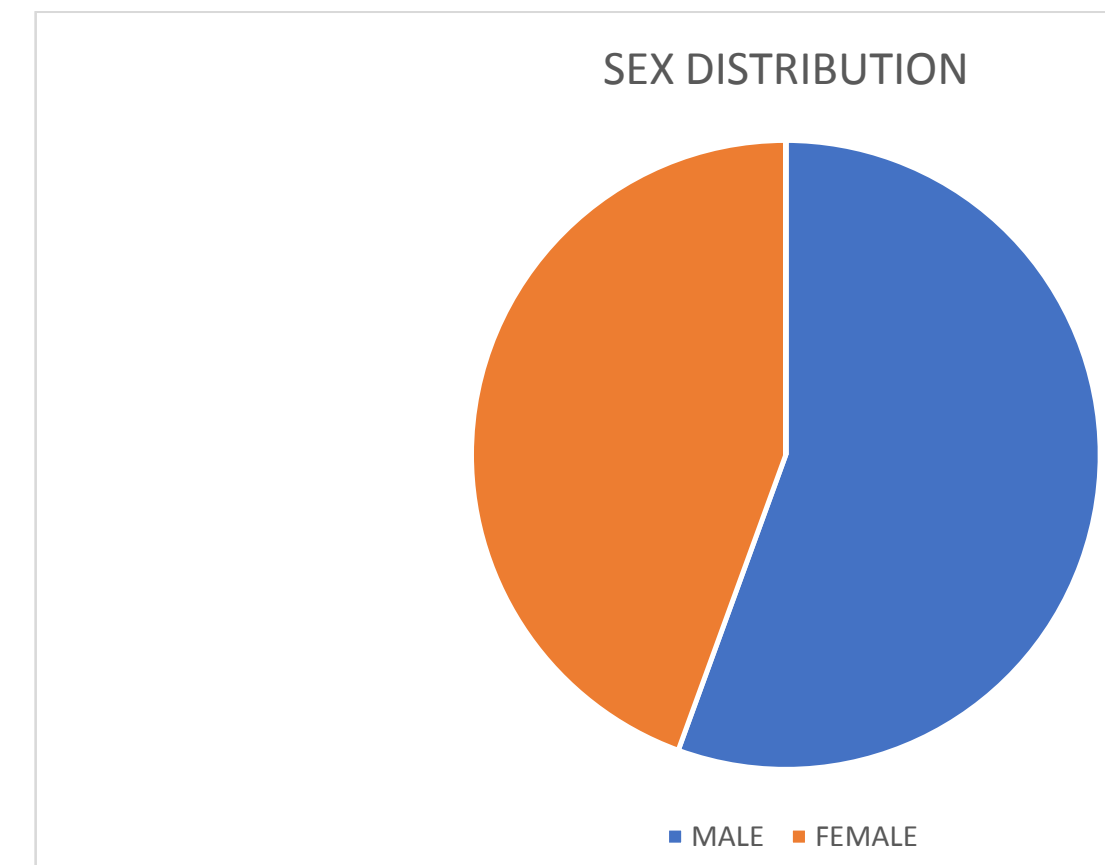

The average age was $23.4 \pm$ years, and there were 4 males and 6 females.

Followed by a single skin incision, three umbilical ports were placed in one case, with an additional right iliac fossa needloscopic instrument. The remaining 9 cases two umbilical ports and an additional right iliac fossa needloscopic instrument was used out of which one case underwent conversion to a convention all aparoscopic approach due to difficult instrumentation.

The mean operative time was $57 \pm 40 \mathrm{~min}$, calculated from time of insertion of ports to skin closure. The average intraoperative blood loss was $7.5 \pm 5 \mathrm{~mL}$.

\section{Table 3}

\begin{tabular}{|c|c|c|}
\hline EVENTS & NUMBER OF PATIENTS & PERCENTAGE \\
\hline INTRAOP COMPLICATIONS & & \\
\hline Bowel injury & 0 & \\
\hline Vascular injury & 0 & \\
\hline OPERATIVE TIME & 8 & $80 \%$ \\
\hline $30-60$ mins & 2 & \\
\hline $60-90$ mins & 1 & $10 \%$ \\
\hline CONVERSION & 0 & \\
\hline Multiport & & \\
\hline Open & 0 & \\
\hline POSTOP COMPLICATION & 0 & \\
\hline Paralytic ileus & 0 & \\
\hline Peritonitis & 1 & \\
\hline Intestinal obstruction & & \\
\hline Wound infection & & \\
\hline
\end{tabular}

There was no incidence of increase intraoperative bleed or gut injury in SIMPLA technique. The time taken for bowel movement (passing stool) was $2.1 \pm 0.6$ days. Only the patient with the perforated appendix required drain which was removed on the third post-operative day. Most patients $^{(6)}$ were allowed orally on second post operative day and discharged on the third post- 
operative day. Three patients were discharged on the second post-operative day, and the case with the appendicular perforation was discharged on the fourth post-operative day.

\section{Discussion}

Our experience demonstrates the safety, feasibility and superior cosmetic outcome of SIMPLA. It, however, presents a technical challenge to the operating surgeons due to difficult triangulation of instruments, hence time consuming in the beginning. However with experience and better learning curve, SIMPLA which can be performed using the conventional laparoscopic instruments, can gain increasing importance as it provides better cosmesis.

\section{Conclusion}

We propose that SIMPLA technique using conventional multiport instruments is simple, feasible, cost effective alternative to conventional laparoscopic appendicectomy with superior cosmetic outcomes with no significant post operative complications.

\section{References}

1. Prystowsky JB, Pugh CM, Nagle AP. Current problems in surgery: appendicitis. Curr Probl Surg.2005;42:688-742. doi: 10.1067/j.cpsurg.2005.07.003. [PubMed] [CrossRef] [Google Scholar]

2. Mishra RK, Hanna GB, Cuschieri A. Laparoscopic versus open appendectomy for the treatment ofacute appendicitis. World J Laparosc Surg. 2008;1(1):19-28. doi: $\quad 10.5005 / j p$-journals-100071043.[CrossRef] [Google Scholar]

3. Bucher P, Ostermann S, Pugin F, Morel PE. E-notes appendectomy versus transvaginal appendectomy: similar cosmetic results but shorter complete recovery? Surg Endosc. 2009;23(4):916917. doi: 10.1007/s00464-008-0284-3. [PubMed] [CrossRef] [Google Scholar]
4. A Technique of Single-Incision Laparoscopic Appendectomy Using, Conventional Multiport Laparoscopic Instruments (SILACI): Preliminary, Experience of 32 Cases. S. K. Uday, C. H. Venkata Pavan Kumar, and P. R. K. Bhargav. [PubMed] [CrossRef] [Google Scholar]

5. Single-incision multi-port laparoscopic appendectomy: How I do it. Bhatia P, Sabharwal V, Kalhan S, John S, Deed JS, Khetan M. J Minim Access Surg. 2011 Jan;7(1):28-32. doi: 10.4103/09729941.72372

6. Pisanu A, Porceddu G, Reccia I, Saba A, Uccheddu A. Meta-analysis of studies comparing single incision laparoscopic appendectomy and conventional multiport laparoscopic appendectomy. J Surg Res. 2013;183(2):e49-e59.

doi:

$$
\text { 10.1016/j.jss.2013.03.038. }
$$

[PubMed]

[CrossRef] [Google Scholar]

7. D'Alesio A, Piro E, Tadini B, Beretta F. One-trocar transumbilical laparoscopicassisted appendectomy in children: our experience. Eur J Pediatr Surg. 2002; 12:24-27. doi: 10.1055/s-2002-25096. [Abstract] [CrossRef] [Google Scholar]

8. Curcillo PG, Podolsky ER (2010) Re: single incision multiport laparoendoscopic (SIMPLE) surgery. Surg Endosc 24:20762077- https://doi.org/10.1007/s00464-0100894-4

9. Li P, Chen Z-H, Li Q-G, Qiao T, Tian YY, Wang DR (2013) Safety and efficacy of single-incision laparoscopic surgery for appendectomies: a meta-analysis. World J Gastroenterol 19:4072-4082. https://doi.org/10.3748/wjg.v19.i25.4072.

10. Cai Y-L, Xiong X-Z, Wu S-J, Cheng Y, Lu J, Zhang J, Lin YX, Cheng NS (2013) Single-incision laparoscopic appendectomy vs conventional laparoscopic appendectomy: systematic review and meta-analysis. World J Gastroenterol 
19:5165-5173.

https://doi.org/10.3748/wjg.v19.i31.5165

11. Ahmed I, Cook JA, Duncan A et al (2015)

Single port/incision laparoscopic surgery compared with standard three-port laparoscopic surgery for appendicectomy: a randomized controlled trial. Surg Endosc 29:77-85. https://doi.org/10.1007/s00464014-3416-y. 